\title{
Mobile 4G LTE Networks Mobility and Coverage for Some Locations in Ibadan Using Path Loss Analysis
}

\author{
O.E. Ogunsola \\ Department of Physics \\ University of Ibadan \\ Ibadan, Nigeria \\ E-mail: \\ seyiogunsola22@gmail.com \\ Tel. No.: +2348050253416
}

\author{
O. Adekele \\ Department of Computer Science \\ University of Ibadan \\ Ibadan, Nigeria
}

\author{
O.I. Olaluwoye \\ Department of Physics \\ University of Ibadan \\ Ibadan, Nigeria
}

\begin{abstract}
The recent migration of most GSM service providers' networks in Ibadan from $3 G$ to $4 G$, in preparation for the deployment of $5 G$ technology in the nation necessitated the need to re-examine the GSM networks' mobility and coverage within the micro cells inbetween a Base Station and a Mobile Station. This attempt is aimed at using existing Path Loss Propagation Models in proffering solutions to the negative consequences usually associated with call drops in the Urban and Suburban Areas of Ibadan due to inability of channels to handover as a result of path loss. The path loss (dB) analysis was carried out by measuring the Received Signal Strength RSS (dBm) at distances ranging from $0.05 \mathrm{~km}$ to $4 \mathrm{~km}$ in-between Base Stations and Mobile Stations using the factory fitted installed RSS software on Android phones. These measurements were taken for three weeks within the urban and suburban areas of the University of Ibadan campus, and its neighborhood community of Agbowo for ten selected existing Base Stations from four of the nationwide GSM Service Providers (SP1, SP2, SP3 and SP4) in Nigeria. The variation of path loss with the RSS for GSM Service Provider (SP1) propagating at $955 \mathrm{MHz}$ (reference distance of $0.05 \mathrm{~km}$ ), $1850 \mathrm{MHz}$ and $2120 \mathrm{MHz}$, were 66.03 $\mathrm{dB}, 71.77 \mathrm{~dB}$ and $72.96 \mathrm{~dB}$, respectively. However, at $4 \mathrm{~km}$ the path loss had risen to $101.59 \mathrm{~dB}$ for $955 \mathrm{MHz}$, $103.81 \mathrm{~dB}$ for $1850 \mathrm{MHz}$ and $105 \mathrm{~dB}$ for $2120 \mathrm{MHz}$. Also, the path loss for the GSM service provider (SP2) propagating at $960 \mathrm{MHz}$ (reference distance of $0.05 \mathrm{~km}$ ), $1865 \mathrm{MHz}$ and $2150 \mathrm{MHz}$ were $66.07 \mathrm{~dB}, 71.84 \mathrm{~dB}$ and
\end{abstract}

$73.08 \mathrm{~dB}$, respectively. Moreover, in a similar manner to the SP1 service provider, at $4 \mathrm{~km}$ the path loss had risen to $104.14 \mathrm{~dB}$ for $960 \mathrm{MHz}, 109.9 \mathrm{~dB}$ for $1865 \mathrm{MHz}$ and 111.14dB for 2150MHz. Furthermore, the path loss for the GSM service provider (SP3) propagating at $950 \mathrm{MHz}$ (reference distance of $0.05 \mathrm{~km}$ ), $1835 \mathrm{MHz}$ and $2130 \mathrm{MHz}$ were $65.98 \mathrm{~dB}, 71.70 \mathrm{~dB}$ and $73.00 \mathrm{~dB}$, respectively. Likewise, as was in the case of the SP1 and SP2 Service providers, the path loss at $4 \mathrm{~km}$ had risen to $104.05 \mathrm{~dB}$ for $950 \mathrm{MHz}, 109.76 \mathrm{~dB}$ for $1835 \mathrm{MHz}$ and $111.06 \mathrm{~dB}$ for 2130MHz. Also, the path loss for the GSM service provider (SP4) propagating at $940 \mathrm{MHz}$ (reference distance of $0.05 \mathrm{~km}$ ), $1880 \mathrm{MHz}$ and $2140 \mathrm{MHz}$, were 65.47 $\mathrm{dB}, 71.46 \mathrm{~dB}$ and $72.23 \mathrm{~dB}$, respectively. Moreover, the path loss at $4 \mathrm{~km}$ had risen to $103.53 \mathrm{~dB}$ for $940 \mathrm{MHz}$, $109.52 \mathrm{~dB}$ for $1880 \mathrm{MHz}$ and $110.29 \mathrm{~dB}$ for $2140 \mathrm{MHz}$ as was the case with the other GSM Service providers (SP!, SP2 and SP3) considered.Thus, the path loss increases with distance within the microcells of base stations. However, the path loss model with minimum path loss (dB) at a given distance enhances good coverage and handover postponement. Moreover, the mean square error values used in obtaining the accuracy between the measured and the Empirical models were 17.15dB, 59.69dB, 48.46dB, 60.52dB and 40.07dB for the $C$-model, Cost-OH, Sub-O, Lee-model and experimental model, respectively.

Key words: GSM networks, Base station, Mobile station, Signal strength, GSM service provider 


\section{INTRODUCTION}

Path loss or path attenuation is the reduction in the amplitude of electromagnetic waves travelling through space due to energy loss in the path between the transmitter and the receiver system. Signal path loss analysis plays a pivotal role in the design of radio communication system. The evaluation of path loss is very important from the Network Planning Level (NPL) to the link budgeting stage.

Thus, path loss measurement and monitoring provides helping tool in the determination of wireless communication (for voice and data) Quality of service (QoS) at NPL stage $[1,2]$. The poor Received Signal Strength (RSS) at the receiver terminal is majorly caused by path loss $[3,4,5]$. However, mobile network mobility (traffic) can be varied with traffic parameters (bandwidth, delay, loss and availability).

In mobile network, the small area covered by a Base Station Transceiver (BST) is called a microcell. Moreover, there are several small overlapping areas within a BST. Hence, the closed distance cells require different frequencies in order for interference to be minimised, while for macro cell same frequency is required. However, it must be noted that all wireless communication operation requires the use of Key Performance Indicators (KPI) in accessing their network performance and QoS evaluation.

The coverage in a mobile communication is divided into a number of cells [6]. Hence, whenever a mobile unit is moving from one cell to an adjacent cell handover occurs. In essence, handover occurs by changing cells within the same BTS and the effect is more when movement is from one Mobile Station (MS) to another. However, a call is dropped when there is no channel to handover to within a MS. This happened when hand over initiation is not followed by handover execution.[1]. Also, path loss parameters such as transmitter power, transmitter location, antenna gain, antenna height, receiver sensitivity and the type of transmission analysis are helpful in radio communication system. In essence, path loss estimation is therefore a required parameter in determining both the Quality of Service (QoS) and signal strength at different locations before communication equipments are installed.

\section{A. Path Loss Propagation Models}

Several propagation models already developed have been used over the years to predict signal coverage [7] which is very essential in the design of all $4 \mathrm{G}$ mobile networks. These propagation models are also important in predicting the path loss effect on radio system NPL which can be used as the controlling factor in system performance and coverage for better QoS at reception. Some of these path loss models include:

(i) Free space Path Loss Model

(ii) Clutter Factor Model

(iii) Okumura's-Hata Model

(iv) COST231- Hata

(v) Lee Model

(vi) Log-distance path loss Model

\section{B Free space Path Loss Model}

This model takes into account a scenario where the propagated wave radiates freely to an infinite distance without being absorbed or reflected $[8,9]$. This ideal case is not practicable in real life situations and is as presented in equation1:

$P l(d B)_{F S}=32.4+20 \log \left(f_{c}\right)+20 \log D$

\section{Clutter Factor Model}

This proposed model consists of the plane earth loss plus an extra loss component called the clutter factor to the existing factors taken into consideration by various models [10]. This was done by assigning $\mathrm{k}$ and $\mathrm{n}$ for different frequencies and environments using the model [11] which considered large number of measurements taken from some American cities. The total loss defined by this model is obtained by using equation 2 :

$P l(d B)_{C F}=76.3+40 \log D+20 \log _{c}-20 \log _{b}-10 \log _{m}\left(h_{m} \triangle 0 m\right)$

\section{COST231- Hata Model}

The COST-HATA model was enhanced by the European COST 231 project (cooperation of scientific and Technical research) for the purpose of extending the limitations of the HATA models and to apply appropriate correction factors [12] as shown in equations 3 and 4 :

$P l(d B)_{U}=41.33+33.9 \log _{c}-13.82 \log h_{b}+x(\log D)-R+k_{m}$

$R=3.2\left(\log \left(11.75 h_{m}\right)^{2}\right)$ and $k_{m}=3 d B$ 
$P l(d B)_{S U}=41.33+33.9 \log _{c}-13.82 \log g_{b}+x(\log D)-R+k_{m}$

$R=3.2\left(\log \left(11.75 h_{m}\right)^{2}\right)$ and $k_{m}=0 d B$

\section{E. Okumura's-Hata Model}

This is a simple mathematical model obtained as a function of frequency $\left(f_{c}\right)$ antenna heights, path loss exponent (n) and distance in equations 5, 6 and 7 , respectively by Okumura, from empirical data in Tokyo from his observations of what was designed $[1] .$.
(4) This Model is the commonly used path loss empirical model and it divides the prediction area into open $\left(\mathrm{Pl}_{\mathrm{OP}}\right)$, suburban $\left(\mathrm{Pl}_{\mathrm{SU}}\right)$ and urban $\left(\mathrm{Pl}_{\mathrm{U}}\right)[6]$. Okumura's-Hata is very suitable for frequency operation of $150-1500 \mathrm{MHz}$, at a distance of $1 \mathrm{~km}$ to $20 \mathrm{~km}$. In addition, the base station antenna height $\left(\mathrm{h}_{\mathrm{b}}\right)$ of above $30 \mathrm{~m}$ and mobile station height $\left(\mathrm{h}_{\mathrm{m}}\right)$ of $3 \mathrm{~m}$ are also utilised as correction factors.

$P l(d B)_{U}=74.52+26.16 \log f_{c}-13.82 \log h_{b}+x \log D-y$

$f_{c} \geq 300 \mathrm{MHz}$

$P l(d B)_{S U}=54.15+26.16 \log f_{c}-13.82 \log h_{b}+x \log D-2\left(\log \left(f_{c} / 28\right)^{2}\right)$

$f_{c} \geq 300 \mathrm{MHz}$

$P l(d B) o p=28.61+26.16 \log f_{c}-13.82 \log h_{b}+x \log D-z$

where

$y=3.2\left(\log \left(11.75 h_{m}\right)^{2}\right)$

$x=44.9-6.55 \log h_{b}$

$z=4.78\left(\log f_{c}\right)^{2}+18.38 \log f_{c}$

$D=\operatorname{dis} \tan c e(\mathrm{~km})$

$f_{c}=$ Frequency of transmission

$h_{m}=1.5 \mathrm{~m}$

$h_{b}=36 m$

\section{F. Lee Model}

Lee model is a power law model, derived from measurements in different locations, using a procedure for estimating an effective base station antenna height for variations in terrain as shown in equation $8[1]$.

$P l(d B)_{L}=29-20 \log h_{b(e f f)}+n \log D-P_{o}$

Where, $\mathrm{n}$ and $\mathrm{P}_{\mathrm{o}}$ are given by measurements, and $\mathrm{h}_{\mathrm{b}(\mathrm{eff})}$ is the effective base station antenna height

\section{G. Log-distance path loss Model (i.e. Experimental Model)}

The log-distance path loss propagation models shows that the coverage received signal power decreases logarithmically with distance for outdoor or indoor radio channels [10]. The mean path loss for an arbitrary Transmiter-Receiver (T-R) distance is expressed as a function of distance, using path loss exponent (n) as shown in equations 9 and 10

$$
P l(d B)=P l\left(d_{0}\right)+10 n \log \left(d / d_{0}\right)
$$

where

$n=$ the path loss exponent

$d_{0}=$ the closed - in reference dis $\tan c e$

$d=$ the Tx - Rx dis $\tan c e$

$n=\frac{\sum_{i=1}^{k}\left(P l\left(d_{0}\right)-P l\left(d_{0}\right)\right)}{\sum_{i=1}^{k}\left[10 L \log _{10}\left(d_{i} / d_{0}\right)\right]}$ 


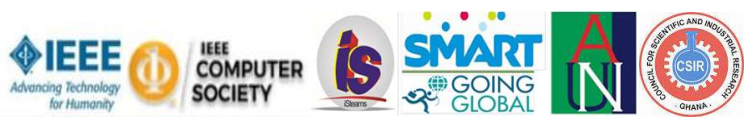

However, it must be noted that path loss parameters have been modelled by researchers, but report has shown that the existing models are not appropriate when deployed in areas outside the limit of which it was originally designed [8]. Moreover, in migrating from $3 \mathrm{G}$ to $4 \mathrm{GLTE}$, field measurements are required in determining the mobility, handover and coverage of signals in mobile network and also in planning for the $5 \mathrm{G}$ mobility $[13,14]$.

Thus, this research is aimed at improving the quality of wireless services by carrying out site dependent measurements with a view to determining the suitable and acceptable Path loss model required.

However, measurements would be carried out for mobile communication network providers in Nigeria operating at GSM mobile frequencies of 900 $\mathrm{MHz}, 1800 \mathrm{MHz}$ and $2100 \mathrm{MHz}$. Furthermore, in this work, the comparative analysis of path loss for 4GLTE networks in the urban and rural environmental area shall be carried out within the University of Ibadan campus and its neighborhood Agbowo community, Ibadan. Moreover, the results obtained shall be compared with the already existing path loss propagating models such as Clutter Factor, Okumura-Hata, COST-231 and Lee, amongst others.

\section{METHODOLOGY}

Data measurements were taken at various locations within the University of Ibadan campus and its neighborhood of Agbowo community. The base stations were classified into two: the Urban and Suburban areas. The parameter for determining the sub-urban area was based strictly on the low traffic density of the considered locations. Also, the buildings in this vicinity were mainly bungalows with some sparsely located storey buildings of about two to three floors. It was observed that these suburban locations are mainly on U.I. campus namely: Faculty of Science, CBN, Amina way, Carver way1, Carver way 2, Libra way including Alabanla, located at Agbowo. However, the choice of the urban locations was based on the high density of both human and vehicular traffic, including compactly built storey-buildings and offices with communication towers. These urban locations are mainly at Agbowo namely: Transformer, Major Salawu, Ogunyemi including Jaja clinic at UI.
The Received Strength Signal (RSS) measurements $(\mathrm{dBm})$ were taken from Nigeria's GSM mobile spectrum [15] for four GSM service providers (SP1, SP2, SP3 and SP4) transmitting at: frequencies of $940 \mathrm{MHz}, 950 \mathrm{MHz}, 955 \mathrm{MHz}$, $960 \mathrm{MHz}, \quad 1835 \mathrm{MHz}, \quad 1850 \mathrm{MHz}, \quad 1865 \mathrm{MHz}$, $1880 \mathrm{MHz}, 2120 \mathrm{MHz}, 2130 \mathrm{MHz}, 2140 \mathrm{MHz}$ and $2150 \mathrm{MHz}$. These RSS measurements were taken using the signal strength software installed on Android phone for each of these frequencies within the microcell of Base station and Mobile station at $50 \mathrm{~m}$ intervals each from $0.05 \mathrm{~km}$ to $4 \mathrm{~km}$, for three consecutive weeks on a daily basis at $08 \mathrm{Hr}, 12 \mathrm{Hr}$, $15 \mathrm{Hr}$ and $17 \mathrm{Hr}$. These RSS $(\mathrm{dBm})$ measurements were further utilised in determining the path loss.

The technical wireless parameters of an Israeli based communication company [9] were adopted and modified in order for the path loss values to be correctly analysed for the test locations.

\section{RESULTS}

The four GSM service providers' path loss and RSS were analysed for coverage strength and call handover within the microcells over the test distance. The path loss was determined using equation1.

\section{A.Variation of Path Loss (PL) and Received Signal Strength (RSS) of GSM provider (SP1)}

The variation of path loss with the RSS for GSM service provider (SP1) propagating at $955 \mathrm{MHz}$, $1850 \mathrm{MHz}$ and $2120 \mathrm{MHz}$ for $4 \mathrm{G}$ signal with distance was presented in Table I. The path loss was 66.03 $\mathrm{dB}$ at the reference distance $0.05 \mathrm{~km}$ for the 955 $\mathrm{MHz}, 71.77 \mathrm{~dB}$ for $1850 \mathrm{MHz}$ and $72.96 \mathrm{~dB}$ for $2120 \mathrm{MHz}$. Also, the corresponding RSS values were $-38.03 \mathrm{dBm},-43.77 \mathrm{dBm}$ and $-44.96 \mathrm{dBm}$ respectively. At $4 \mathrm{~km}$ the path loss had risen to $101.59 \mathrm{~dB}$ for $955 \mathrm{MHz}, 103.81 \mathrm{~dB}$ for $1850 \mathrm{MHz}$ and $105 \mathrm{~dB}$ for $2120 \mathrm{MHz}$ with the RSS valves -70.07 $\mathrm{dBm},-81.83 \mathrm{dBm}$ and $-83.02 \mathrm{dBm}$ respectively. It showed that the value of path loss increases with distance within the microcells of the base station. Call drop due to hand over problem can occur due to increase path loss despite that the RSS values look quite good. 
TABLE I: PATH LOSS (dB) AND RSS (dBm) FOR VARIOUS FREQUENCY SPECTRUM FOR GSM SERVICE PROVIDER ONE (SP1)

\begin{tabular}{|c|c|c|c|c|c|c|}
\hline \multicolumn{7}{|c|}{ SP1 } \\
\hline & \multicolumn{2}{|c|}{$955 \mathrm{mHz}$} & \multicolumn{2}{|c|}{$1850 \mathrm{mHz}$} & \multicolumn{2}{|c|}{$2120 \mathrm{mHz}$} \\
\hline $\mathrm{D}(\mathrm{km})$ & $\mathrm{PL}(\mathrm{dB})$ & $\mathrm{RSS}(\mathrm{dBm})$ & $\mathrm{PL}(\mathrm{dB})$ & RSS(dBm) & $\mathrm{PL}(\mathrm{dB})$ & $\mathrm{RSS}(\mathrm{dBm})$ \\
\hline 0.05 & 66.03 & -38.03 & 71.77 & -43.77 & 72.96 & -44.96 \\
\hline 0.1 & 72.05 & -44.05 & 77.79 & -49.79 & 78.98 & -50.98 \\
\hline 0.15 & 75.57 & -47.57 & 81.32 & -53.32 & 82.5 & -54.5 \\
\hline 0.2 & 78.07 & -50.07 & 83.81 & -55.81 & 85 & -57 \\
\hline 0.25 & 80.01 & -52.01 & 85.75 & -57.75 & 86.94 & -58.94 \\
\hline 0.3 & 81.59 & -53.59 & 87.34 & -59.34 & 88.52 & -60.52 \\
\hline 0.35 & 82.93 & -54.93 & 88.67 & -60.67 & 89.86 & -61.86 \\
\hline 0.4 & 84.09 & -56.09 & 89.83 & -61.83 & 91.02 & -63.02 \\
\hline 0.45 & 85.11 & -57.11 & 90.86 & -62.86 & 92.04 & $\begin{array}{l}-64.04 \\
\end{array}$ \\
\hline 0.5 & 86.03 & -58.03 & 91.77 & -63.77 & 92.96 & -64.96 \\
\hline 1 & 92.05 & -64.05 & 97.79 & -69.79 & 98.98 & -70.98 \\
\hline 2 & 98.07 & -70.07 & 103.81 & -75.81 & 105 & -77 \\
\hline 3 & 101.59 & -73.59 & 107.34 & -79.34 & 108.52 & -80.52 \\
\hline 4 & 104.09 & -76.09 & 109.83 & -81.83 & 111.02 & -83.02 \\
\hline
\end{tabular}

B. Variation of Path Loss (PL) and Received Signal Strength (RSS) of GSM provider (SP2)

The variation of path loss with the RSS for GSM service provider (SP2) propagating at $960 \mathrm{MHz}$, $1865 \mathrm{MHz}$ and $2150 \mathrm{MHz}$ for $4 \mathrm{G}$ signal with distance up to $4 \mathrm{~km}$ was presented in Table II. The path loss was $66.07 \mathrm{~dB}$ at the reference distance $0.05 \mathrm{~km}$ and for $960 \mathrm{MHz}, 71.84 \mathrm{~dB}$ for $1865 \mathrm{MHz}$ and $73.08 \mathrm{~dB}$ for $2150 \mathrm{MHz}$.
Also, the corresponding RSS values were -38.03 $\mathrm{dBm},-38.07 \mathrm{dBm}$ and $-43.84 \mathrm{dBm}$ respectively. At 4 $\mathrm{km}$ the path loss had risen to $104.14 \mathrm{~dB}$ for $960 \mathrm{MHz}$, $109.9 \mathrm{~dB}$ for $1865 \mathrm{MHz}$ and $111.14 \mathrm{~dB}$ for $2150 \mathrm{MHz}$ with the RSS valves $-76.14 \mathrm{dBm},-81.90 \mathrm{dBm}$ and$83.14 \mathrm{dBm}$ respectively. The path loss increases with distance within the microcells of the base station also. Call drop due to hand over problem can occur due to increase path loss as high as $111.14 \mathrm{~dB}$ though the RSS values look quite good. 
TABLE II: PATH LOSS (dB) AND RSS (dBm) FOR VARIOUS FREQUENCY SPECTRUM FOR GSM SERVICE PROVIDER TWO (SP2

\begin{tabular}{|r|r|r|r|r|r|r|}
\hline \multicolumn{7}{|c|}{ SP2 } \\
\hline & \multicolumn{7}{|c|}{$960 \mathrm{MHz}$} & \multicolumn{2}{c|}{$1865 \mathrm{MHz}$} & \multicolumn{2}{|c|}{$2150 \mathrm{MHz}$} \\
\hline $\mathrm{D}(\mathrm{km})$ & $\mathrm{PL}(\mathrm{dB})$ & $\mathrm{RSS}(\mathrm{dBm})$ & $\mathrm{PL}(\mathrm{dB})$ & $\mathrm{RSS}(\mathrm{dBm})$ & $\mathrm{PL}(\mathrm{dB})$ & $\mathrm{RSS}(\mathrm{dBm})$ \\
\hline 0.05 & 66.07 & -38.07 & 71.84 & -43.84 & 73.08 & -45.08 \\
\hline 0.1 & 72.1 & -44.1 & 77.86 & -49.86 & 79.1 & -51.1 \\
\hline 0.15 & 75.62 & -47.62 & 81.39 & -53.39 & 82.62 & -54.62 \\
\hline 0.2 & 78.12 & -50.12 & 83.88 & -55.88 & 85.12 & -57.12 \\
\hline 0.25 & 80.05 & -52.05 & 85.82 & -57.82 & 87.06 & -59.06 \\
\hline 0.3 & 81.64 & -53.64 & 87.41 & -59.41 & 88.64 & -60.64 \\
\hline 0.35 & 82.98 & -54.98 & 88.74 & -60.74 & 89.98 & -61.98 \\
\hline 0.4 & 84.14 & -56.14 & 89.9 & -61.9 & 91.14 & -63.14 \\
\hline 0.45 & 85.15 & -57.15 & 90.93 & -62.93 & 92.16 & -64.16 \\
\hline 0.5 & 86.07 & -58.07 & 91.84 & -63.84 & 93.08 & -65.08 \\
\hline 1 & 92.1 & -64.1 & 97.86 & -69.86 & 99.1 & -71.1 \\
\hline 2 & 98.12 & -70.12 & 103.88 & -75.88 & 105.12 & -77.12 \\
\hline 3 & 101.64 & -73.64 & 107.41 & -79.41 & 108.64 & -80.64 \\
\hline 4 & 104.14 & -76.14 & 109.9 & -81.9 & 111.14 & -83.14 \\
\hline
\end{tabular}

C. Variation of Path Loss (PL) and Received Signal Strength (RSS) of GSM provider (SP3)

The variation of path loss with the RSS for GSM service provider (SP3) propagating at $950 \mathrm{MHz}$, $1835 \mathrm{MHz}$ and $2130 \mathrm{MHz}$ for $4 \mathrm{G}$ signal with distance up to $4 \mathrm{~km}$ was presented in Table III. The path loss for the $950 \mathrm{MHz}$ was $65.98 \mathrm{~dB}$ at the reference distance of $0.05 \mathrm{~km}, 71.70 \mathrm{~dB}$ for $1835 \mathrm{MHz}$ and 73.00 $\mathrm{dB}$ for $2130 \mathrm{MHz}$.
Also, the corresponding RSS values were -38.03 $\mathrm{dBm},-37.98 \mathrm{dBm}$ and $-43.70 \mathrm{dBm}$ respectively. At 4 $\mathrm{km}$ the path loss had risen to $104.05 \mathrm{~dB}$ for $950 \mathrm{MHz}$, $109.76 \mathrm{~dB}$ for $1835 \mathrm{MHz}$ and $111.06 \mathrm{~dB}$ for $2130 \mathrm{MHz}$ with the RSS valves $-76.05 \mathrm{dBm},-81.76 \mathrm{dBm}$ and$83.06 \mathrm{dBm}$ respectively. The path loss increases with distance within the microcells of the base station also. Call drop due to hand over problem can occur due to increase in path loss as high as $111.06 \mathrm{~dB}$ though the RSS values look quite good. 
TABLE III: PATH LOSS (dB) AND RSS (dBm) FOR VARIOUS FREQUENCY SPECTRUM FOR GSM SERVICE PROVIDER THREE (SP3)

\begin{tabular}{|c|c|c|c|c|c|c|}
\hline \multicolumn{7}{|c|}{ SP3 } \\
\hline & \multicolumn{2}{|c|}{$950 \mathrm{mHz}$} & \multicolumn{2}{|c|}{$1835 \mathrm{mHz}$} & \multicolumn{2}{|c|}{$2130 \mathrm{mHz}$} \\
\hline $\mathrm{D}(\mathrm{km})$ & $\mathrm{PL}(\mathrm{dB})$ & $\mathrm{RSS}(\mathrm{dBm})$ & $\mathrm{PL}(\mathrm{dB})$ & $\mathrm{RSS}(\mathrm{dBm})$ & $\mathrm{PL}(\mathrm{dB})$ & $\mathrm{RSS}(\mathrm{dBm})$ \\
\hline 0.05 & 65.98 & -37.98 & 71.70 & -43.70 & 73.00 & -45.00 \\
\hline 0.1 & 72.00 & -44.00 & 77.72 & -49.72 & 79.02 & -51.02 \\
\hline 0.15 & 75.53 & -47.53 & 81.24 & -53.24 & 82.54 & -54.54 \\
\hline 0.2 & 78.03 & -50.03 & 83.74 & -55.74 & 85.04 & -57.04 \\
\hline 0.25 & 79.96 & -51.96 & 85.68 & -57.68 & 86.98 & -58.98 \\
\hline 0.3 & 81.55 & -53.55 & 87.27 & -59.27 & 88.60 & -60.60 \\
\hline 0.35 & 82.89 & -54.89 & 88.60 & -60.60 & 89.90 & -61.90 \\
\hline 0.4 & 84.05 & -56.05 & 89.76 & -61.76 & 91.06 & -63.06 \\
\hline 0.45 & 85.07 & -57.07 & 90.79 & -62.79 & 92.08 & -64.08 \\
\hline 0.5 & 85.98 & -57.98 & 91.70 & -63.70 & 93.00 & -65.00 \\
\hline 1 & 92.00 & -64.00 & 97.72 & -69.72 & 99.02 & -71.02 \\
\hline 2 & 98.03 & -70.03 & 103.74 & -75.74 & 105.04 & -77.04 \\
\hline 3 & 101.55 & -73.55 & 107.27 & -79.27 & 108.56 & -80.56 \\
\hline 4 & 104.05 & -76.05 & 109.76 & -81.76 & 111.06 & -83.06 \\
\hline
\end{tabular}

D. Variation of Path Loss (PL) and Received Signal Strength (RSS) of GSM provider (SP4)

The variation of path loss with the RSS for GSM service provider (SP4) propagating at $940 \mathrm{MHz}$, $1880 \mathrm{MHz}$ and $2140 \mathrm{MHz}$ for $4 \mathrm{G}$ signal with distance up to $4 \mathrm{~km}$ was presented in Table IV. The path loss for the $940 \mathrm{MHz}$ at the reference distance of $0.05 \mathrm{~km}$ was $65.47 \mathrm{~dB}, 71.46 \mathrm{~dB}$ for $1880 \mathrm{MHz}$ and $72.23 \mathrm{~dB}$ for $2140 \mathrm{MHz}$. Also, the corresponding RSS values were $-37.47 \mathrm{dBm},-43.46 \mathrm{dBm}$ and $-44.23 \mathrm{dBm}$ respectively. At $4 \mathrm{~km}$ the path loss had risen to $103.53 \mathrm{~dB}$ for $940 \mathrm{MHz}, 109.52 \mathrm{~dB}$ for $1880 \mathrm{MHz}$ and $110.29 \mathrm{~dB}$ for $2140 \mathrm{MHz}$ with the RSS valves -75.53 $\mathrm{dBm},-81.52 \mathrm{dBm}$ and $-82.29 \mathrm{dBm}$ respectively.
The path loss increases with distance within the microcells of the base station also. Call drop due to hand over problem can occur due to increase in path loss. 
TABLE IV: PATH LOSS (dB) AND RSS (dBm) FOR VARIOUS FREQUENCY SPECTRUM FOR GSM SERVICE PROVIDER FOUR (SP4)

\begin{tabular}{|c|c|c|c|c|c|c|}
\hline \multicolumn{7}{|c|}{ SP4 } \\
\hline & \multicolumn{2}{|c|}{$940 \mathrm{mHz}$} & \multicolumn{2}{|c|}{$1880 \mathrm{mHz}$} & \multicolumn{2}{|c|}{$2140 \mathrm{mHz}$} \\
\hline $\mathrm{D}(\mathrm{km})$ & $\overline{P L}(\mathrm{~dB})$ & $\mathrm{RSS}(\mathrm{dBm})$ & $\mathrm{PL}(\mathrm{dB})$ & $\mathrm{RSS}(\mathrm{dBm})$ & $\mathrm{PL}(\mathrm{dB})$ & $\mathrm{RSS}(\mathrm{dBm})$ \\
\hline 0.05 & 65.47 & -37.47 & 71.46 & -43.46 & 72.23 & -44.23 \\
\hline 0.1 & 71.49 & -43.49 & 77.48 & -49.48 & 78.25 & -50.25 \\
\hline 0.15 & 75.01 & -47.01 & 81.11 & -53.11 & 81.77 & -53.77 \\
\hline 0.2 & 77.51 & -49.51 & 83.5 & -55.5 & 84.27 & -56.27 \\
\hline 0.25 & 79.45 & -51.45 & 85.44 & -57.44 & 86.21 & -58.21 \\
\hline 0.3 & 81.03 & -53.03 & 87.03 & -59.03 & 87.79 & -59.79 \\
\hline 0.35 & 82.37 & -54.37 & 88.36 & -60.36 & 89.13 & -61.13 \\
\hline 0.4 & 83.53 & -55.53 & 89.52 & -61.52 & 90.29 & -62.29 \\
\hline 0.45 & 84.55 & -56.55 & 90.55 & -62.55 & 91.31 & -63.31 \\
\hline 0.5 & 85.47 & -57.47 & 91.46 & -63.46 & 92.23 & -64.23 \\
\hline 1 & 91.49 & -63.49 & 97.48 & -69.48 & 98.25 & -70.25 \\
\hline 2 & 97.51 & -69.51 & 103.5 & -75.5 & 104.27 & -76.27 \\
\hline 3 & 101.03 & -73.03 & 107.03 & -79.03 & 107.79 & -79.79 \\
\hline 4 & 103.53 & -75.53 & 109.52 & -81.52 & 110.29 & -82.29 \\
\hline
\end{tabular}

\section{E. RSS (dBm) Hourly Fluctuation f the GSM Service} Providers

The fluctuations of the average signal strength of the various GSM Service Providers with distance for specific hours of the day ( $08 \mathrm{hrs}, 12 \mathrm{hrs}$ and $17 \mathrm{hrs})$ for all the locations (Urban and suburban) considered is as presented in Figures $1-6$.
The path loss effect on RSS( $\mathrm{dBm})$ enhance the fluctuation as distance increases in both the urban and sub urban locations during the specified hours of the day . However, the value of RSS reduction was very significant within the $3-4 \mathrm{~km}$ distance for all the service providers. Moreover, the effects of microcell inter hand over challenge within channels is also visible. 


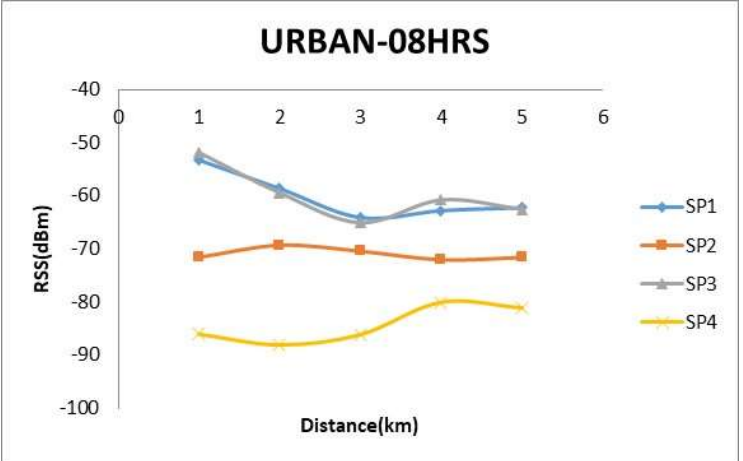

Figure 1: GSM Service providers' RSS(dBm) temporal fluctuations for urban $08 \mathrm{hrs}$

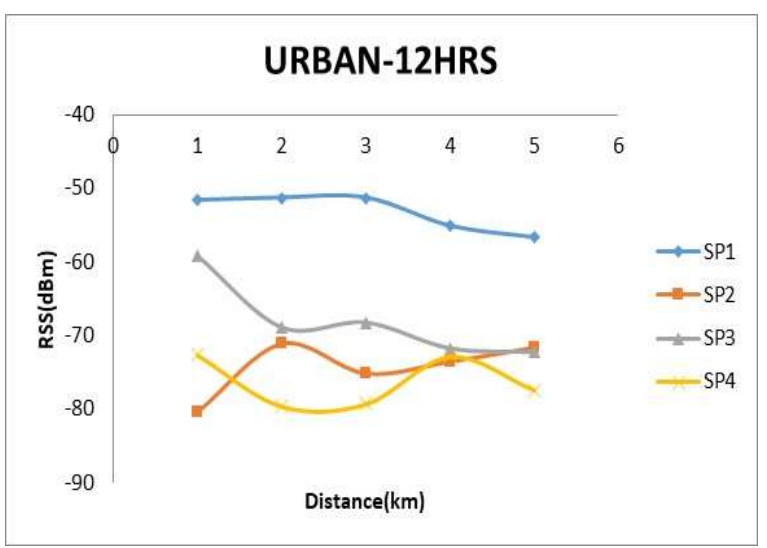

Figure 2: GSM Service providers' RSS(dBm) temporal fluctuations for urban $12 \mathrm{hrs}$

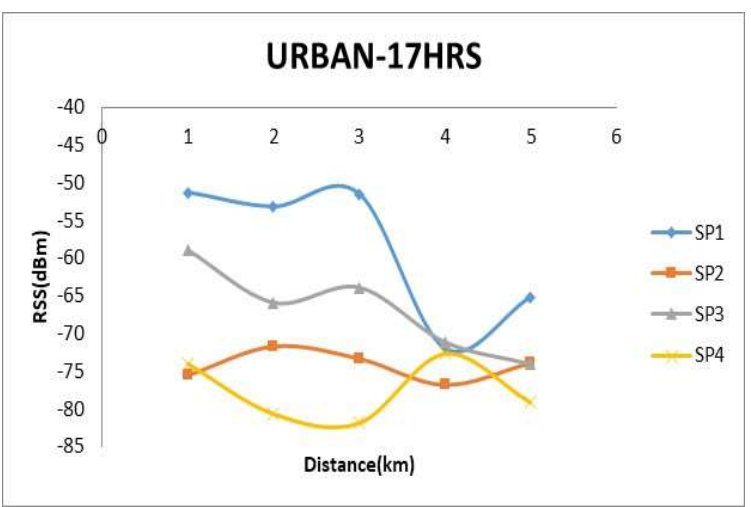

Figure 3: GSM Service providers' RSS(dBm) temporal fluctuations for urban $17 \mathrm{hrs}$

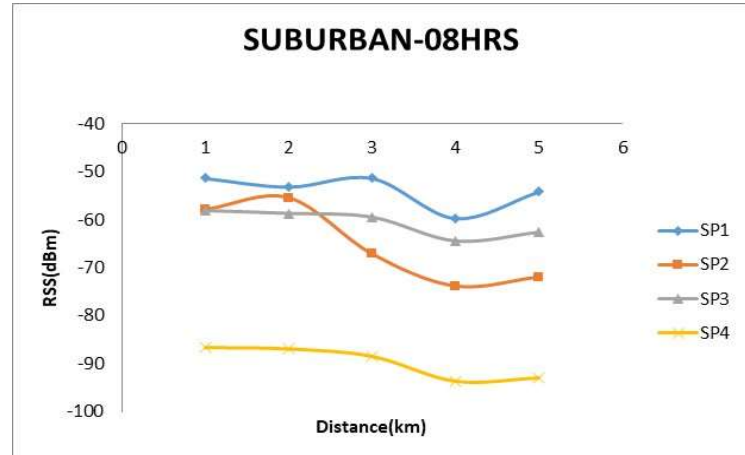

Figure 4: GSM Service providers' RSS(dBm) temporal fluctuations for suburban $08 \mathrm{hrs}$

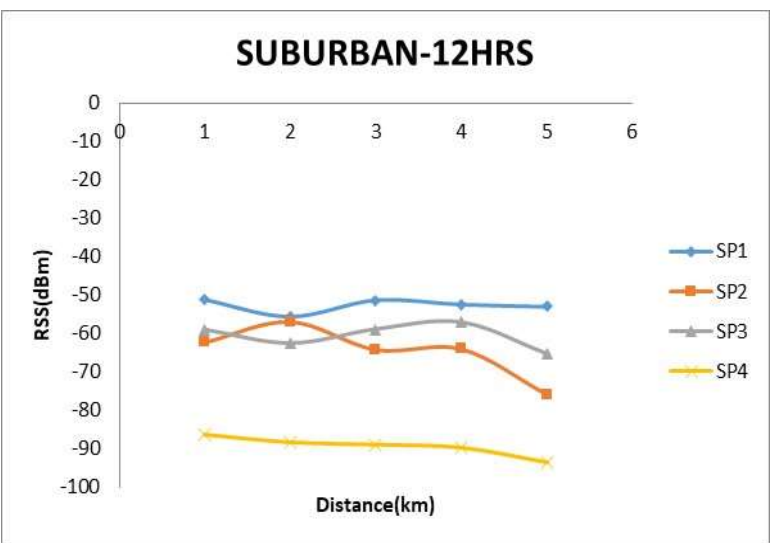

Figure 5: GSM Service providers' RSS(dBm) temporal fluctuations for suburban $12 \mathrm{hrs}$

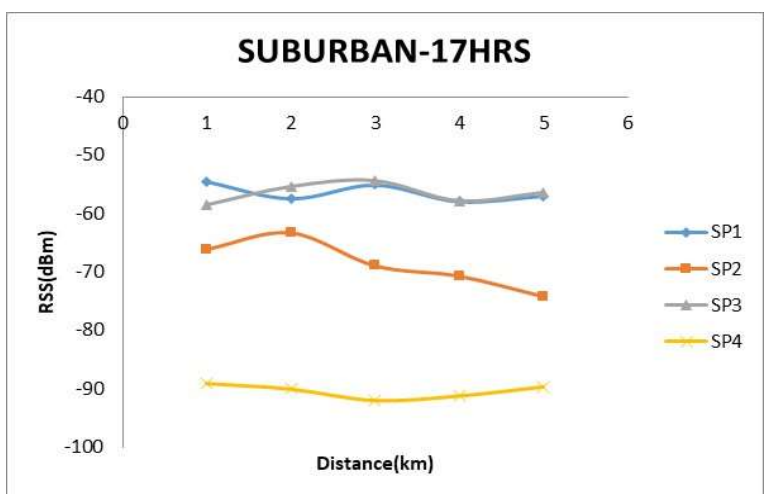

Figure 6: GSM Service providers' RSS(dBm) temporal fluctuations for suburban $17 \mathrm{hrs}$ 
F. RSS (dBm) and GSM frequencies (900 MHz, 1800 $\mathrm{MHz}$ and $2100 \mathrm{MHz})$

The average Received Signal Strength, RSS(dBm) information that can be useful in the GSM signal budget link estimation for all SP's and for

communication system design and planning in Ibadan, Nigeria is as presented in Table $\mathrm{V}$

TABLE V: THE DAILY VARIATION IN AVERAGE RECEIVED SIGNAL STRENGTH ACROSS THE GSM SERVICE PROVIDER'S FREQUENCY SPECTRUM (SP) FOR THE TESTED URBAN AND SUBURBAN AREAS AT UI AND AGBOWO BETWEEN 8AM AND 5PM.

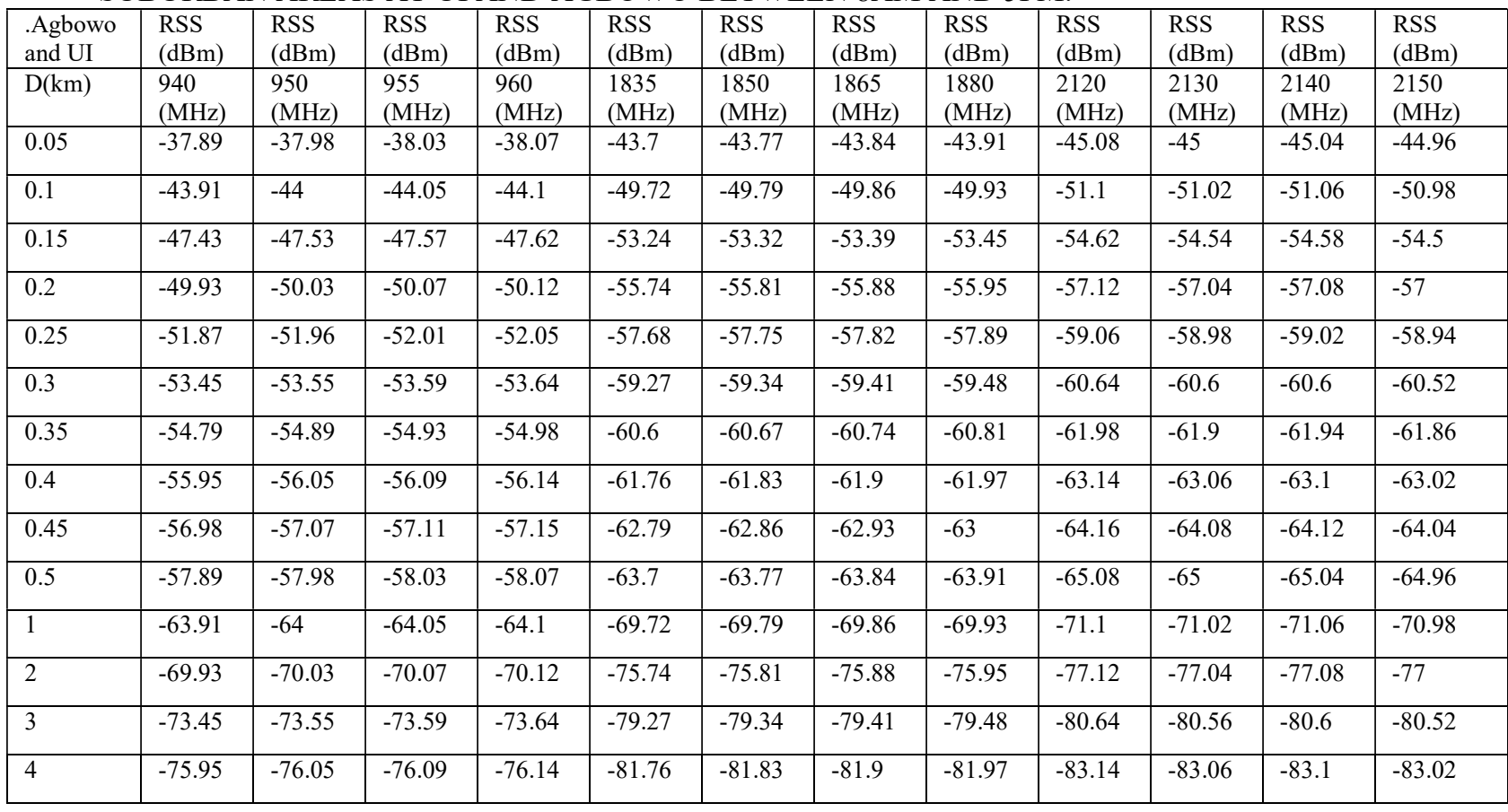

G. Path Loss Exponent (n) for GSM providers for Experimental Model

The experimental Path loss model for the location was determined by using the location parameters. These values of $n$ (Table VI) were obtained by using equations 9 and 10 and the test information for the locations. These test information includes distance from the base station, the whole frequencies of SP1, SP2, SP3, SP4 providers, transmission powers of $44 \mathrm{dBm}, \mathrm{h}_{\mathrm{m}}$ of 1.5 meters, $\mathrm{h}_{\mathrm{b}}$ of 36meter , distance D $(0.05-4.0) \mathrm{km}$ and frequencies, $\mathrm{f}_{\mathrm{c}}(\mathrm{Sp}$ 's).
TABLE VI: MAXIMUM PATH LOSS EXPONENT (n) FOR ALL GSM PROVIDERS FREQUENCIES

\begin{tabular}{|l|l|}
\hline GSM Providers & Path loss Exponent (n) \\
\hline SPI & 2.117529 \\
\hline SP2 & 2.548445 \\
\hline SP3 & 2.000518 \\
\hline SP4 & 2.152145 \\
\hline
\end{tabular}

\section{H. Experimental and Empirical Path Loss Models} for Urban and suburban Areas

The received signal strength (RSS) and Path loss (PL) from the base stations' micro and macro cells using various path loss models were calculated 
against distance from Base Station to Mobile Station at three different frequencies 900, 1800 and 2100 $\mathrm{MHz}$ for all the considered GSM service providers (SP1, SP2, SP3 and SP4) and were presented in figures 7 to 10 . The Free Space Model was obtained by using equation 1, Clutter Factor model was obtained from equation 2, COST231- Hata model was obtained using equations 3 and 4 , and Lee model was obtained using equation 8. All these models were compared with the Log-distance path loss model (i.e. Experimental Model) obtained from equations 9 and 10 and the substitution of the corresponding Path loss exponent (n) obtained in Table 10.
I. Comparison between Experimental and Empirical Path Loss Models for Urban and suburban Areas of SP1 and SP2

The location test parameters for GSM-SP1 $\left(\mathrm{f}_{\mathrm{c}}=\right.$ $955,1850,2120 \mathrm{MHz}, h_{m}=1.5 \mathrm{~m}$ and $\left.h_{b}=36 \mathrm{~m}\right)$ and for GSM-SP2 $\left(\mathrm{f}_{\mathrm{c}}=960,1865,2150 \mathrm{MHz}, h_{m}=1.5 \mathrm{~m}\right.$ and $\left.h_{b}=36 \mathrm{~m}\right)$ were substituted into the appropriate equations (1-10) as applicable. The results obtained were as presented in Table VII, and Figures 7 and 8. All these models overestimated the Experimental model except Lee model which under estimated it.

TABLE VII: PATH LOSS MODELS FOR GSM-SP1 AND GSM-SP2 FREQUENCY BANDS IN IBADAN

\begin{tabular}{|c|c|c|c|c|c|}
\hline Path loss Model & $\mathrm{f}(\mathrm{MHz})$ & GSM-SP1 & Path loss Model & $\mathrm{f}(\mathrm{MHz})$ & GSM-SP2 \\
\hline C-Model & 2120 & $109.92+40 \operatorname{LogD}$ & C-Model & 2150 & $110.06+40 \log D$ \\
\hline Cost_H & & $155.78+34.71 \log \mathrm{D}$ & Cost_H & & $155.99+34.71 \log \mathrm{D}$ \\
\hline Sub-OH & & $144.16+34.71 \log \mathrm{D}$ & Sub-OH & & $144.37+34.71 \log \mathrm{D}$ \\
\hline Urban-OH & & $156.63+34.71 \log \mathrm{D}$ & Urban-OH & & $156.83+34.71 \log \mathrm{D}$ \\
\hline Experimental & & $89.57+21.2 \log \mathrm{D}$ & Experimental & & $89.57+21.2 \log \mathrm{D}$ \\
\hline Lee-Model & & $58.81+38.4 \log \mathrm{D}$ & Lee-Model & & $58.81+38.4 \log \mathrm{D}$ \\
\hline Path loss Model & $\mathrm{f}(\mathrm{MHz})$ & SP1 & Path loss Model & $\mathrm{f}(\mathrm{MHz})$ & SP2 \\
\hline C-Model & 1850 & $108.75+40 \log \mathrm{D}$ & C-Model & 1865 & $108.89+40 \log \mathrm{D}$ \\
\hline Cost_H & & $153.78+34.71 \log \mathrm{D}$ & Cost_H & & $153.92+34.71 \log \mathrm{D}$ \\
\hline Sub-OH & & $142.59+34.71 \log \mathrm{D}$ & Sub-OH & & $142.69+34.71 \log \mathrm{D}$ \\
\hline Urban-OH & & $154.62+34.71 \log \mathrm{D}$ & Urban-OH & & $154.74+34.71 \operatorname{LogD}$ \\
\hline Experimental & & $89.57+21.2 \log \mathrm{D}$ & Experimental & & $89.57+21.2 \log \mathrm{D}$ \\
\hline Lee-Model & & $58.81+38.4 \log \mathrm{D}$ & Lee-Model & & $58.81+38.4 \log \mathrm{D}$ \\
\hline Path loss Model & $\mathrm{f}(\mathrm{MHz})$ & SP1 & Path loss Model & $\mathrm{f}(\mathrm{MHz})$ & SP2 \\
\hline C-Model & 955 & $103.01+40 \log \mathrm{D}$ & C-Model & 960 & $103.05+40 \log \mathrm{D}$ \\
\hline Cost_H & & $144.07+34.71 \log \mathrm{D}$ & Cost_H & & $144.15+34.71 \log \mathrm{D}$ \\
\hline Sub-OH & & $134.78+34.71 \log \mathrm{D}$ & Sub-OH & & $134.78+34.71 \log \mathrm{D}$ \\
\hline Urban-OH & & $144.88+34.71 \log \mathrm{D}$ & Urban-OH & & $144.88+34.71 \log D$ \\
\hline Experimental & & $89.57+21.2 \log \mathrm{D}$ & Experimental & & $89.57+21.2 \log \mathrm{D}$ \\
\hline Lee-Model & & $58.81+38.4 \log \mathrm{D}$ & Lee-Model & & $58.81+38.4 \log \mathrm{D}$ \\
\hline
\end{tabular}




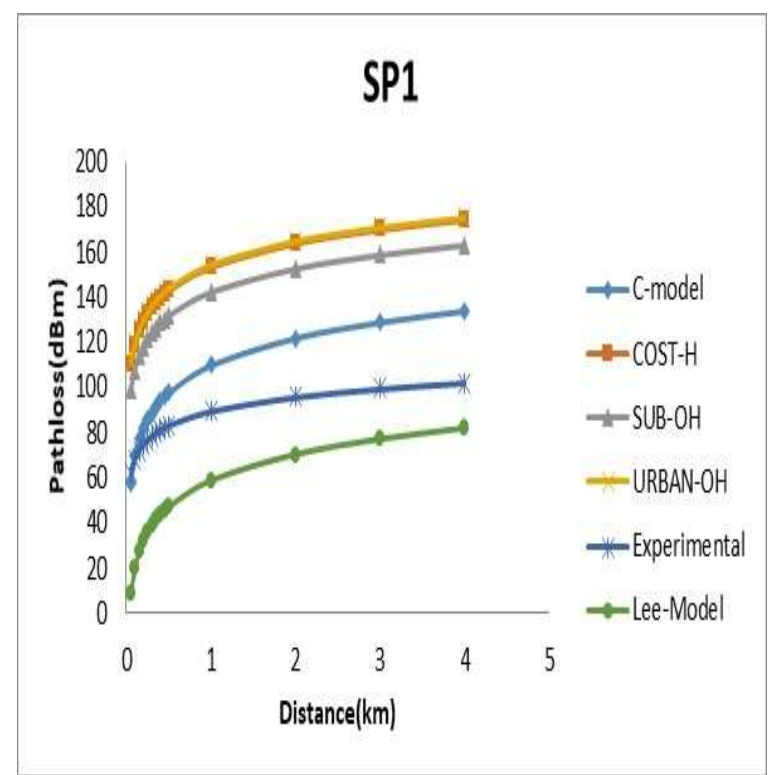

Figure 7: Path Loss Comparison for SP1 at a constant distance from Base station

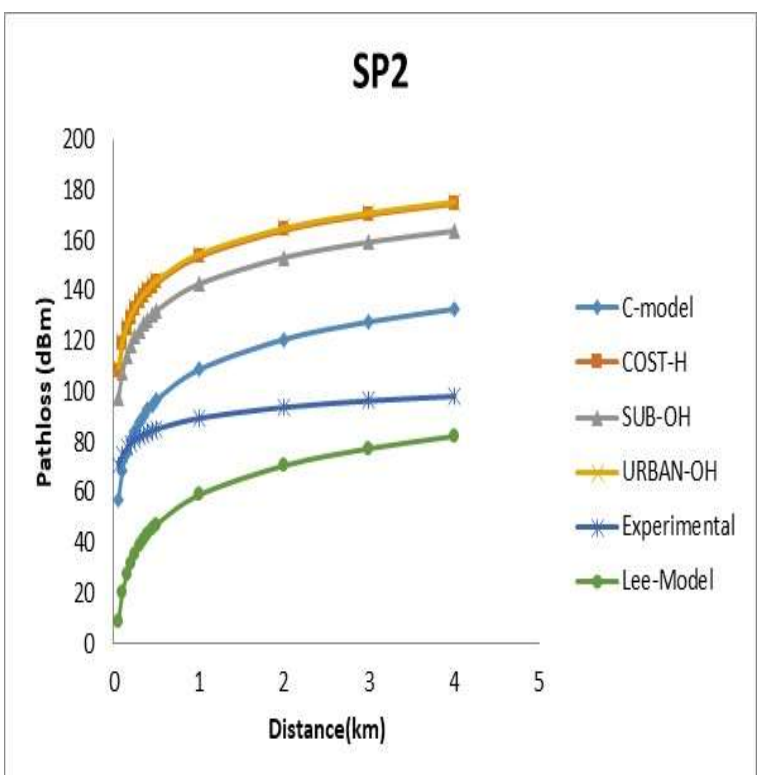

Figure 8: Path Loss Comparison for SP2 at a constant distance from Base station
J. Comparison between Experimental and Empirical Path Loss Models for Urban and suburban Areas of SP3 and SP4

The location test parameters for GSM-SP3 $\left(\mathrm{f}_{\mathrm{c}}=\right.$ $950,1835,2130 \mathrm{MHz}, h_{m}=1.5 \mathrm{~m}$ and $\left.h_{b}=36 \mathrm{~m}\right)$ and for GSM-SP4 $\left(\mathrm{f}_{\mathrm{c}}=940,1880,2140 \mathrm{MHz}, h_{m}=1.5 \mathrm{~m}\right.$ and $\left.h_{b}=36 \mathrm{~m}\right)$ were substituted into the appropriate equations (1-10) as applicable.

The results obtained were as presented in Table VIII, and Figures 9 and 10. All these models overestimated the Experimental model except Lee model which under estimated it. 
TABLE VIII: PATH LOSS MODELS FOR GSM-SP3 AND GSM-SP4 FREQUENCY BANDS IN IBADAN

\begin{tabular}{|c|c|c|c|c|c|}
\hline Path loss Model & $\mathrm{f}(\mathrm{MHz})$ & GSM-SP3 & Path loss Model & $\mathrm{f}(\mathrm{MHz})$ & GSM-SP4 \\
\hline C-Model & 2130 & $109.98+40 \log \mathrm{D}$ & C-Model & 2140 & $110.02+40 \log \mathrm{D}$ \\
\hline Cost_H & & $155.85+34.71 \log \mathrm{D}$ & Cost_H & & 155.92+34.71LogD \\
\hline Sub-OH & & $144.22+34.71 \log \mathrm{D}$ & Sub-OH & & $144.27+34.71 \log \mathrm{D}$ \\
\hline Urban-OH & & 156.69+34.71 LogD & Urban-OH & & $156.77+34.71 \log \mathrm{D}$ \\
\hline Experimental & & $89.57+21.2 \log \mathrm{D}$ & Experimental & & $89.57+21.2 \log \mathrm{D}$ \\
\hline Lee-Model & & $58.81+38.4 \log \mathrm{D}$ & Lee-Model & & $58.81+38.4 \log \mathrm{D}$ \\
\hline Path loss Model & $\mathrm{f}(\mathrm{MHz})$ & SP3 & Path loss Model & f(MHz) & SP4 \\
\hline C-Model & 1835 & $108.60+40 \log \mathrm{D}$ & C-Model & 1880 & $108.89+40 \log \mathrm{D}$ \\
\hline Cost_H & & $153.66+34.71 \log \mathrm{D}$ & Cost_H & & $154.92+34.71 \log \mathrm{D}$ \\
\hline Sub-OH & & $142.50+34.71 \log \mathrm{D}$ & Sub-OH & & $142.7+34.71 \log \mathrm{D}$ \\
\hline Urban-OH & & $154.50+34.71 \log \mathrm{D}$ & Urban-OH & & $154.86+34.71 \log \mathrm{D}$ \\
\hline Experimental & & $89.57+21.2 \log \mathrm{D}$ & Experimental & & $89.57+21.2 \log \mathrm{D}$ \\
\hline Lee-Model & & $58.81+38.4 \log \mathrm{D}$ & Lee-Model & & $58.81+38.4 \log \mathrm{D}$ \\
\hline Path loss Model & $\mathrm{f}(\mathrm{MHz})$ & SP3 & Path loss Model & $\mathrm{f}(\mathrm{MHz})$ & SP4 \\
\hline C-Model & 950 & $102.96+40 \log \mathrm{D}$ & C-Model & 940 & $102.87+40 \log \mathrm{D}$ \\
\hline Cost_H & & $143.99+34.71 \log \mathrm{D}$ & Cost_H & & $143.84+34.71 \log \mathrm{D}$ \\
\hline Sub-OH & & $134.59+34.71 \log \mathrm{D}$ & Sub-OH & & $134.59+34.71 \log \mathrm{D}$ \\
\hline Urban-OH & & $144.72+34.71 \log \mathrm{D}$ & Urban-OH & & 144.65+34.71LogD \\
\hline Experimental & & $89.57+21.2 \log \mathrm{D}$ & Experimental & & $89.57+21.2 \log \mathrm{D}$ \\
\hline Lee-Model & & $58.81+38.4 \log \mathrm{D}$ & Lee-Model & & $58.81+38.4 \log \mathrm{D}$ \\
\hline
\end{tabular}




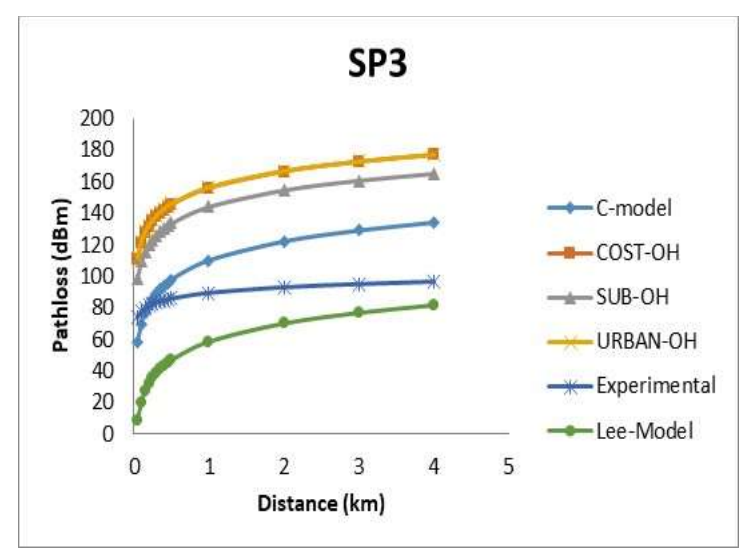

Figure 9: Path Loss Comparison for SP3 at a constant distance from Base station

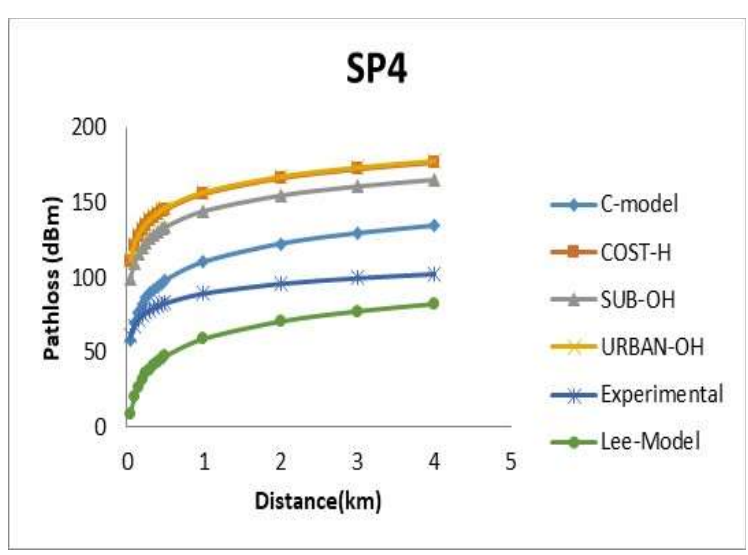

Figure 10: Path Loss Comparison for SP4 at a constant distance from Base station

Table IX: Mean square Error (MSE) for all the GMS service Providers considered at the Location in Ibadan.

\begin{tabular}{|l|r|r|r|r|r|}
\hline & C-model & Cost-OH & Sub-O & Lee-model & Experimental model \\
\hline SP1 & 16.85 & 59.76 & 48.65 & 60.58 & 38.09 \\
\hline SP2 & 16.76 & 57.72 & 46.80 & 58.54 & 41.49 \\
\hline SP3 & 18.07 & 59.24 & 47.91 & 60.07 & 42.77 \\
\hline SP4 & 16.91 & 62.03 & 50.46 & 62.87 & 40.07 \\
\hline Mean & 17.15 & 59.68 & 48.45 & 60.52 & \\
\hline
\end{tabular}

$M S E=\sqrt{\sum_{i=1}^{K}\left(\frac{\left(P_{E}-P_{r}\right)^{2}}{N}\right)}$

Where, $P_{r}$ is the Empirical model used predicted values and $P_{E}$ is the measured values for each instance of distance, $d$.

The overestimation and underestimation was due to the differences in the physical development of Tokyo and Europe from where the models were originally developed, unlike Ibadan Nigeria where this present work is carried out. Thus, in order to improve on the accuracy of the utilised Empirical models, the mean square error (MSE) between the measured and the Empirical models (Table IX) were calculated using equation 11 .
This MSE values were $17.15 \mathrm{~dB}, 59.69 \mathrm{~dB}$, $48.46 \mathrm{~dB}, 60.52 \mathrm{~dB}$ and $40.07 \mathrm{~dB}$ for the C-model, Cost-OH, Sub-O, Lee-model and experimental model, respectively. 


\section{CONCLUSION}

The path loss calculations for radio and wireless survey tools determined by signal strength at different locations were presented. This type of wireless survey tool is essential in determining radio signal strengths before installing any communication equipment. The parameters necessary to determine handover measurements are the received signal strength, the signal to noise ratio and the bit error rate. However, it is important to note that RSS measurements are affected by path loss which is dependent on distance. The RSS and Path loss from test locations were calculated at three frequencies: 900, 1800 and 2100 $\mathrm{MHz}$ for GSM Service providers SP1, SP2, SP3 and SP4 using different path loss models. However, the Model with minimum path loss value reduces the

number of handoffs and also enhances good coverage and handover postponement. Moreover, handover measurements provide information on mobility in GSM network, coverage and the quality of service. Also, the mean square error values used in obtaining the accuracy between the measured and the empirical models were $17.15 \mathrm{~dB}, 59.69 \mathrm{~dB}, 48.46 \mathrm{~dB}, 60.52 \mathrm{~dB}$ and $40.07 \mathrm{~dB}$ for the C-model, Cost-OH, Sub-O, Leemodel and experimental model, respectively.

\section{REFERENCES}

[1] Archana, Sharma, J.P., Sharma, D. \& Sharma, P. K. (2014). Outdoor Propagation Path Loss Models: A Review. International Journal of Scientific \& Engineering Research. 5(4), 1109.

[2] Kumar, K.A.M. (2011). Significance of Empirical and Physical Propagation Models to Calculate the Excess Path Loss. Journal of Engineering Research and Studies. 3(5), 223-228.

[3] Adeleke, O., Ojo, J.S., \& Ajewole, M.O. (2014). Determination of the calibration factor for the rain rate derived from TRMM satellite using MRR data over Akure, Nigeria. International Journal of Emerging Trends in Science and Technology. 1(7), 1151-1165.

[4] Prajesh, P. \& Singh, R. K. (2011). A survey on various propagation model for wireless communication. $5^{\mathrm{TH}}$ IEEE International Conference on Advanced Computing and Communication Technology, 62.

[5] Khan, J. (2010). Handover management in GSM cellular system. International Journal of Computer Application. 8(12), 1424.

[6] Azubogu, A.C.O., Okoli, G.N., Idigo, V.E. \& Ohaneme, C.O. (2010). EmpiricalStatistical Propagation Path loss Model for Suburban environment of Nigeria at $800 \mathrm{MHz}$ band. The IUP Journal of Science and Technology, 7(2), 45-54.

[7] Purnima, K.S. \& Singh, R.K. (2012). Cell Coverage Area and Link Budget Calculation in GSM System. International Journal of Modern Engineering Research. 2 (2), 170176

[8] Freeman R. L. (2007). Radio System Design for Telecommunications, New Jersey: John Willey.http://www.breezecom.com. Retrieved October 22nd, 2020. 
[10] Ifeagwu E.N. \& Edeko, A. . (2015). Characterization of Mobile Radio Propagation Channel using Empirically based Path loss Model for Suburban Environments in Nigeria. International Journal on Recent and Innovation Trends in Computing and Communication. 3(5), $3300-3304$.

[11] Egli, J.J. (1957). Radio Propagation above 40MC over Irregular Terrain. Proceedings of the IRE. 45(10), 1383-1391.

[12] Singh, Y. (2012). Comparison of Okumura, Hata and Cost-231 Models on the Basis of Path Loss and Signal Strength.

International Journals of Computer Applications. 59(11), 37-41..

[13] Erceg, V., Greenstein, L.J., Ijandra, S.Y.,Pakoff, S.R., Gupta, A., Kulic, B., Julius, A.A. \& Bianchi, r. (1999). An empirically path loss model for wire-less channels in suburban environment. IEEE journals on selected areas of communications. 17, 1205-1211.
[14] Sharma, D. \& Singh, R. K. (2012). Analysis of Handover Initiation Using Path Loss to Sustain QoS. International Journal of Scientific and Engineering Research. 3(5), 1-6.

[15] http://www.ncc.ng.or. Retrieved October 22nd, 2020. 